\title{
Médiévales
}

Langues, Textes, Histoire

73 | automne 2017

Le texte à l'épreuve du numérique

\section{L'historien et ses démons. Autour de quelques travaux récents sur la démonologie médiévale}

Julien Véronèse

\section{(2) OpenEdition}

1 Journals

Édition électronique

URL : https://journals.openedition.org/medievales/8244

DOI : 10.4000/medievales.8244

ISSN : $1777-5892$

Éditeur

Presses universitaires de Vincennes

Édition imprimée

Date de publication : 15 décembre 2017

Pagination : 213-239

ISBN : 978-2-84292-801-8

ISSN : 0751-2708

Référence électronique

Julien Véronèse, "L'historien et ses démons. Autour de quelques travaux récents sur la démonologie médiévale », Médiévales [En ligne], 73 | automne 2017, mis en ligne le 28 février 2019, consulté le 22 avril 2022. URL : http://journals.openedition.org/medievales/8244 ; DOI : https://doi.org/10.4000/ medievales.8244 


\section{Julien Véronèse}

\section{L'historien et ses démons \\ Autour de quelques travaux récents \\ sur la démonologie médiévale}

Lorsqu'un jour je séjournais [...] abandonné dans le monastère du bienheureux martyr Léger, qu'on appelle Champeaux, une nuit, avant l'office de matines, se tint près de moi, au pied du lit, une espèce d'homoncule, d'aspect très répugnant. Pour autant que j'ai pu le discerner en effet, il était de stature moyenne, le cou frêle, le visage maigre, les yeux tout noirs, le front plissé par les rides, le nez écrasé, la bouche proéminente avec des lèvres gonflées, le menton étroit et pointu, une barbe de bouc, les oreilles hérissées et pointues, les cheveux hirsutes, des dents de chien, le crâne pointu, la poitrine enflée, le dos bossu, les fesses qui s'agitaient, les vêtements sordides ${ }^{1}$.

C'est par ces mots que l'historien bourguignon du XI siècle Raoul Glaber livre dans ses célèbres Histoires l'une des descriptions les plus suggestives du démon. On y retrouve quelques traits essentiels, appelés à un bel avenir. Tout d'abord, le caractère hybride et monstrueux, signe de la malignité et de l'altérité démoniaque, conformément à l'imaginaire que la statuaire, l'iconographie ou encore les exempla des prédicateurs vont contribuer à populariser. L'apparition nocturne dont le moine est témoin a ensuite un statut ambigu, emblématique de l'ubiquité démoniaque ; bien qu'elle ait lieu quand Raoul est en train de dormir, autrement dit en songe (l'un des temps et des lieux traditionnels de la suggestion diabolique), elle a toutes les apparences de la réalité ; du reste, elle ne s'interrompt pas immédiatement une fois le moine brutalement réveillé. Si les démons, en se jouant des sens et en influençant l'imagination, sont donc les maîtres de l'illusion et profitent volontiers des rêves pour obséder les chrétiens, les

1. RaOUl Glaber, Histoires, V, 2, traduites et présentées par M. ARnOUX, Turnhout, 1996, p. 274. 
récits, notamment exemplaires, les montrent bien souvent dans toute leur corporéité, voire leur matérialité, agissant physiquement sur l'environnement et les corps. Enfin, pour le moine-historien qui se raconte, cette vision démoniaque est l'aiguillon nécessaire qui va le pousser à faire pénitence et à cheminer vers la vérité ; elle réveille ainsi le traditionnel combat spirituel du moine contre le péché et son principal instigateur, l'antique serpent. Avec d'autres, elle contribue à faire du monastère un îlot de résistance face au « prince de ce monde » et à ses sectateurs, principalement les juifs et les hérétiques si l'on se fie à d'autres passages des Histoires.

Aussi notable soit-il, l'intérêt de Raoul Glaber pour les démons est toutefois à relativiser. Comme l'a montré récemment Jacques Dalarun ${ }^{2}$, ce dernier est moins préoccupé qu'on a pu le dire par ces acteurs indispensables de la psychomachie et de l'eschatologie chrétienne. Le même constat vaut chez d'autres, par exemple chez son contemporain André de Fleury ${ }^{3}$. Dans les Miracles de saint Benoît, les démons possèdent certes les chrétiens qui viennent chercher une guérison miraculeuse au sanctuaire et il arrive qu'ils obsèdent physiquement les moines ; mais, du point de vue de l'hagiographe, ils ne sont que des faire-valoir appelés à être vaincus par le saint et ses successeurs, selon une tradition qui, en dépit de quelques inflexions, va être largement poursuivie par les ordres religieux, notamment mendiants ${ }^{4}$. Il n'est pas jusqu'au célèbre miracle de Théophile, très représenté dans les églises à compter du XII ${ }^{\mathrm{e}}$ siècle, qui ne montre l'échec du diable tentateur face à la volonté individuelle de pénitence : le pacte écrit, que le clerc noue avec le démon par l'entremise d'un magicien juif afin de devenir évêque, est finalement arraché des mains du malin par la Vierge ${ }^{5}$. Le pouvoir de nuisance du diable et, plus encore, de la multitude démoniaque, pour être bien réel, apparaît ainsi étroitement encadré à la fois par la puissance divine et par le libre-arbitre et la foi du fidèle.

Nous verrons, à l'aide de deux cas récemment étudiés, que ce thème traditionnel du combat spirituel connaît de belles heures à la fin du Moyen Âge, tant dans le monde clérical que laïque, au moment où se développent des formes de piété et de dévotion plus individuelles qu'accompagnent à

2. J. DALARUN, « Relire Raoul Glaber », dans D. BARThÉlEMY et R. GRosse éd., Moines et démons. Autobiographie et individualité au Moyen Âge (VII ${ }^{-}$XIII ${ }^{e}$ siècle), Genève, 2014, p. 55-83.

3. D. BARTHÉLEMY, «André de Fleury et les démons », dans BARTHÉLEMY et GrossE éd., Moines et démons..., p. 85-99.

4. F. CHAVE-MAHIR, L'Exorcisme des possédés dans l'Église d'Occident (Xe-XIVe siècle), Turnhout, 2011, p. $266 s q$.

5. P. TEXIER, «Orient, Occident : les avatars du pacte diabolique du clerc Théophile », dans J. HoAreau-DodinaU et P. TeXIER éd., Anthropologies juridiques. Mélanges Pierre Braun, Limoges, 1998, p. 777-798 ; G. KlaniCZAY, I. KRISTÓF et M.-P. GaViano, «Écritures saintes et pactes diaboliques. Les usages religieux de l'écrit (Moyen Âge et Temps modernes) », Annales. Histoire, Sciences Sociales, 56/4-5 (2001), p. 947-980. 
la fois une intériorisation du péché, liée à l'obligation de confession, et la question de plus en plus sensible du discernement des esprits (I). Toutefois, bien qu'il s'agisse de récits illustrant par l'expérience l'action et la fonction des démons, on ne se situe pas là sur le terrain de ce que l'on peut appeler de manière plus stricte la démonologie, à savoir de l'étude rationnelle et scientifique des démons, du moment de leur chute jusqu'aux modalités de leurs interactions avec les hommes. Le développement de la démonologie et de l'anthropologie démoniaque qui l'accompagne est lié pour une part à celui de la méthode scolastique à partir du XII ${ }^{\mathrm{e}}$ siècle, notamment autour des questions d'ordre angélologique. La réflexion sur la nature des anges, leurs hiérarchies, les modalités de leur connaissance et de leurs rapports avec les hommes a eu pour corollaire de faire des démons l'objet d'une recherche théologique plus systématique, notamment à partir des dernières décennies du $\mathrm{XIII}^{\mathrm{e}}$ siècle. Alain Boureau a mis ainsi en évidence un véritable tournant démonologique ou démoniaque à la croisée des XIII ${ }^{\mathrm{e}}$ et $\mathrm{XIV}^{\mathrm{e}}$ siècles $^{6}$ : d'ordre intellectuel, d'une part, marqué par une forme de « libération » des démons (du moins chez certains intellectuels) ; d'ordre juridique, d'autre part, lorsque les pratiques magiques démonolâtres, à la suite d'un certain nombre d'affaires politico-judiciaires, vont être qualifiées d'hérésie à l'initiative du pape Jean XXII (1316-1334). Cette nouveauté juridique montre que l'intérêt pour les démons ne s'inscrit de fait pas uniquement dans un microcosme intellectuel qui a en partie ses dynamiques propres ; il se nourrit aussi du contexte religieux, politique et culturel. Parmi les facteurs généraux qui ont contribué à renforcer progressivement une forme d'obsession démoniaque dans la société tardo-médiévale peuvent être mentionnées les grandes poussées dissidentes et hérétiques qui ont accru la peur d'une subversion de l'ordre chrétien à l'instigation de Satan, au moment même où s'achevait de se construire la monarchie pontificale et la centralisation de l'Église. La « démonisation » des hérétiques et de leurs « sectes » n'est pas une invention du XIII ${ }^{\mathrm{e}}$ siècle, ainsi que le montre entre autres Raoul Glaber ${ }^{7}$; mais le caractère endémique de l'hérésie, sa criminalisation sous le sceau de la lèse-majesté par Innocent III $^{8}$ et la

6. A. BOUREAU, Satan hérétique. Histoire de la démonologie (1280-1330), Paris, 2004.

7. N. CoHn, Europe's Inner Demons : The Demonization of Christians in Medieval Christendom, Chicago, 2001 (nouv. éd. ; [1975]) ; G. G. MERLo, « Membra diaboli. Demoni ed eretici medioevali », Nuova rivista storica, 72, 1988, p. 583-598 ; A. VAUCHEZ, « Diables et hérétiques : les réactions de l'Église et de la société en Occident face aux mouvements religieux dissidents, de la fin du $\mathrm{X}^{\mathrm{e}}$ au début du XII ${ }^{\mathrm{e}}$ siècle », dans Santi e demoni nell'alto medioevo occidentale (secoli V-XI), Spolète, 1989, p. 573-601 ; A. TRIVELLONE, L'Hérétique imaginé. Hétérodoxie et iconographie dans l'Occident médiéval, de l'époque carolingienne à l'inquisition, Turnhout, 2009.

8. J. CHIFFOLEAU, « Note sur la bulle Vergentis in senium, la lutte contre les hérétiques du Midi et la construction des majestés temporelles », dans Innocent III et le Midi, Cahiers de Fanjeaux, 50 (2015), p. 89-114. 
lutte active que lui ont livrée localement les inquisiteurs sous le couvert de l'autorité pontificale lui ont donné une portée nouvelle, alors même que la sphère démoniaque tendait à s'ordonner et la majesté de Satan à se renforcer, du moins symboliquement ${ }^{9}$. Parmi les facteurs à ne pas négliger dans cette promotion des démons et du danger qu'ils représentent, il faut aussi compter sans doute avec l'introduction et la diffusion en Occident, à compter des $\mathrm{XII}^{\mathrm{e}}$ et $\mathrm{XIII}{ }^{\mathrm{e}}$ siècles, de tout un savoir magique d'expression latine pour une large part importé, qui définissait une multitude d'interactions possibles avec les anges et les démons permittente Deo ${ }^{10}$. Largement diffusé dans les milieux cléricaux, voire curiaux, il posait à nouveaux frais la question du pacte superstitieux avec les démons définis par saint Augustin et Isidore de Séville ${ }^{11}$. Certaines de ces traditions proposaient en outre des démonologies en partie alternatives à la doctrine chrétienne, tout en mettant parfois en scène la hiérarchisation (relative) de la société des démons, ainsi que la royauté, voire la majesté démoniaque. L' « hérétisation » des pratiques d' " invocation des démons » et du maleficium au début du XIV siècle se situe ainsi au point de rencontre de ces évolutions d'ordre doctrinal, politique, judiciaire et culturel. Elle est d'autant plus importante qu'elle agit comme un prélude à la chasse d'autres hérétiques démonolâtres, à savoir les sorciers et les sorcières, qui débute dans la première moitié $\mathrm{du} \mathrm{XV}^{\mathrm{e}}$ siècle sous l'égide de démonologues, de juges et de pouvoirs qui ont besoin de s'affirmer. En mobilisant là encore quelques travaux récents ou en cours, nous poursuivrons ce rapide parcours historiographique en faisant le point sur les caractères essentiels des démonologies scolastique et magique (II), avant de dresser le bilan des dernières avancées concernant la sorcellerie et sa persécution au $\mathrm{XV}^{\mathrm{e}}$ siècle, par le biais notamment de quelques affaires de sorcellerie qui mettent en évidence, au sein du processus judiciaire, le jeu à géométrie variable des pouvoirs (III).

9. C. E. Hopkin, The Share of Thomas Aquinas in the Growth of the Witchcraft Delusion, Philadelphie, 1940, p. 47-50 ; A. BourEAU, « Le prince des démons », dans A.H. Allirot, G. LECUPPRE et L. SCORDIA éd., Les Royautés imaginaires (XII ${ }^{e}$-XVI $I^{e}$ siècles), Turnhout, 2005, p. 135-145 ; J. BASCHET, « Satan ou la majesté maléfique dans les miniatures de la fin du Moyen Âge », dans N. NABERT éd., Le Mal et le diable. Leurs figures à la fin du Moyen Âge, Paris, 1996, p. 187-210.

10. J.-P. BoudeT, Entre science et nigromance. Astrologie, divination et magie dans l'Occident médiéval (XII -XV siècle), Paris, 2006 ; F. KLAASSEN, The Transformations of Magic. Illicit Learned Magic in the Later Middle Ages and Renaissance, University Park, 2013.

11. J. VÉRONÈSE, «Faire société avec les démons ? Le magicien et la question du pacte aux derniers siècles du Moyen Âge », Actes des colloques internationaux L'Homme comme animal politique et parlant organisés par G. BRIGUGLIA, S. GENTILI et I. ROSIER-CATACH, Rome (EFR), 2018, sous presse. 


\section{Un homme et une femme face à leurs démons : deux cas d'expérience spirituelle au XIV ${ }^{\mathrm{e}}$ siècle}

En continuité par bien des aspects avec la tradition monastique rapidement évoquée en introduction, les récits (autobiographique ou non) relatant des parcours spirituels individuels, parfois accompagnés d'expériences visionnaires, de plus en plus nombreux à compter du $\mathrm{XII}^{\mathrm{e}}$ siècle, laissent une place notable aux démons ${ }^{12}$. L'âme et sa difficile ascension vers Dieu sont ainsi l'enjeu d'un combat qui prend parfois la forme d'une lutte entre l'ange bon et l'ange mauvais qui, selon une croyance ancienne, accompagent tout homme ${ }^{13}$. La multiplication des cas de charisme visionnaire résultant de pratiques ascétiques et dévotionnelles qui outrepassent souvent la norme, notamment chez des femmes du laïcat urbain, nécessite évidemment un encadrement clérical, qui n'est toutefois pas toujours une garantie contre la suspicion, voire le basculement dans l'hérésie. Elle pose surtout de manière accrue la question de la discretio spirituum, autrement dit de l'origine divine ou, au contraire, démoniaque d'une inspiration (conçue dans les deux cas sur le mode de l'invasion du corps ${ }^{14}$ ) dont le contrôle est d'autant plus nécessaire qu'elle débouche parfois sur des révélations prophétiques. C'est particulièrement vrai là encore lorsqu'il s'agit de femmes dont la faible nature, davantage sujette aux instigations diaboliques selon les clercs, n'est pas tempérée par une quelconque position sociale ou institutionnelle porteuse d'autorité ou de légitimité (à la manière d'une Hildegarde de Bingen). Toutefois, débusquer et anéantir l'œuvre démoniaque souvent subreptice en parvenant à l'identifier (parfois difficilement et au prix d'épreuves), endurer avec patience les vexations parfois brutales des démons sans se détourner de Dieu et sombrer dans la désespérance, sont autant d'épreuves méritoires qui, avec d'autres, permettent de conforter l'âme et concernent tout autant les hommes que les femmes dans l'économie de la relation à Dieu, de la pénitence et du salut.

12. A. BARTOlomei Romagnoli, « Il diavolo nella letteratura mistica del Duecento », dans Il diavolo nel Medioevo, Atti del XIX Convegno internazionale (Todi, 14-17 ottobre 2012), Spolète, 2013, p. 265-305 ; B. NEWMAN, « Possessed by the Spirit : Devout Women, Demoniacs, and the Apostolic Life in the Thirteenth Century », Speculum, 73 (1998), p. 733 770 .

13. P. FAure, «Ange bon et ange mauvais des Pères de l'Église au Moyen Âge », dans J.-P. Boudet, P. FAure et C. Renoux éd., De Socrate à Tintin. Anges gardiens et démons familiers de l'Antiquité à nos jours, Rennes, 2011, p. 79-92. On en a un magnifique exemple chez la béguine du XIII ${ }^{\mathrm{e}} \mathrm{s}$. MeChtILD DE MAGDebOurg, La Lumière fluente de la Divinité, IV, 2, trad. W. VERLAGUET, Grenoble, 2001, p. 107-112, avec notamment un dialogue entre l'« âme » et « ses » diables.

14. N. Caciola, Discerning Spirits. Divine and Demonic Possession in the Middle Ages, Ithaca/Londres, 2003 ; W. L. ANDERSON, The Discernement of Spirits. Assessing Visions and Visionaries in the Late Middle Ages, Tübingen, 2011. 
Deux cas français situés de part et d'autre du XIV ${ }^{\mathrm{e}}$ siècle viennent éclairer sous des jours différents et originaux cette problématique déjà bien défrichée, mais qui mériterait une étude systématique. Le premier concerne un moine, le bénédictin Jean de Morigny, auteur d'une œuvre inclassable, le Liber florum celestis doctrine, parfois connu sous le titre Liber apparicionum et visionum beate et intemerate et sacratissime Virginis Marie; le second, une femme laïque, Ermine de Reims, dont l'expérience est connue par la relation non moins singulière qu'en a fait son confesseur rémois, un certain Jean Le Graveur, qui a en quelque sorte recueilli les aveux de la pieuse femme. Bien qu'il ait subi les affres de la censure, le livre de Jean a connu une large diffusion manuscrite (vingt copies complètes recensées à ce jour, auxquelles s'ajoutent d'autres fragmentaires) ; l'expérience d'Ermine, bien qu'approuvée par le chancelier de l'université de Paris Jean Gerson, est quant à elle restée plus confidentielle (deux manuscrits), conformément du reste au vœu du grand théologien, pour le moins prudent ${ }^{15}$.

Le Liber florum celestis doctrine de Jean de Morigny, encore assez méconnu des médiévistes, vient d'être édité et commenté de manière remarquable ${ }^{16}$. Ce texte volumineux, conservé en deux versions principales (une Antiqua et une Nova compilatio ${ }^{17}$ ), est le fruit d'une rédaction en plusieurs strates, entre 1301 et 1315 , qui accompagnent en partie les révélations célestes dont le moine a bénéficié et dont il ne comprenait pas toujours la portée, lui qui affirme par ailleurs avoir obtenu une première révélation préfiguratrice de son parcours entre douze et quatorze ans et bénéficier du don de prophétie ${ }^{18}$. Jean commence à écrire secrètement (in occulto), alors qu'il est étudiant en droit entre 1300 et 1307 à Orléans

15. F. BONNEY, « Jugement de Gerson sur deux expériences de la vie mystique de son époque : les visions d'Ermine et Jeanne d'Arc », dans Actes du 95e congrès national des Sociétés Savantes, Reims 1970, Paris, 1974, vol. 2, p. 187-195.

16. JOHN OF MORIGNY, Liber florum celestis doctrine. The Flowers of Heavenly Teaching. An Edition and Commentary by C. FANGER and N. WATSON, Toronto, 2015 ; C. FAnGER, Rewriting Magic. An Exegesis of the Visionary Autobiography of A Fourteenth-Century French Monk, University Park, 2015. Les premières études sur ce texte ont été menées par S. BARNAY : «La mariophanie au regard de Jean de Morigny : magie ou miracle de la vision mariale ? », dans Miracles, prodiges et merveilles au Moyen Âge, Paris, 1995, p. 173-190 ; « Désir de voir et interdits visionnaires ou la mariophanie de Jean de Morigny », dans Homo religiosus. Autour de Jean Delumeau, Paris, 1997, p. 519-527.

17. L'Antiqua Compilatio est conservée dans un seul manuscrit, la Nova Compilatio dans 12. D'autres versions remaniées ultérieurement existent. Cf. JOHN OF MORIGNY, Liber florum celestis doctrine..., p. 131-133.

18. JOHN OF MORIGNY, Liber florum celestis doctrine..., III.i.16, p. 314 : « Sciencia ista traxit originem sola gracia [...] ut satis patet per quandam visionem quam habuimus inter duodecim annum etatis nostre et $14^{\mathrm{m}}$, in qua dormiendo visio erat michi quod ego fugiebam a facie inimici persequentis me usque in magna ecclesia Carnocensi. In quam dum intrassem, imago beate Marie vocavit me cum signo brachii et, ad ipsam pergens, sub proteccione mantelli sui posuit me, et ita manus inimici evasi et amplius non timui. » 
pour parfaire sa formation monastique ; puis bientôt avec l'approbation de sa communauté (in publico), alors qu'il est de retour à Morigny et en devient le prévôt en $1308^{19}$. Les apparitions de la Vierge ont deux fonctions principales, intimement liées : d'une part, légitimer le procès d'écriture progressif et douloureux du Liber florum; d'autre part, accompagner le chemin de pénitence auquel se livre le moine. La licencia mariale vient authentifier une expérience intérieure et secrète appelée à devenir exemplaire, que son bénéficiaire entend au minimum ranger parmi les apocryphes chrétiens ${ }^{20}$; mais elle est d'autant plus nécessaire que le Liber n'est pas un récit de visions comme les autres, ou du moins pas exclusivement un récit visionnaire à dimension autobiographique et pénitentielle. En effet, il se conçoit aussi comme un formulaire d'experimenta ou de procédures rituelles, approuvé par la Vierge, permettant au fidèle vertueux d'obtenir des révélations célestes et, surtout, la connaissance instantanée des arts du cursus universitaire. Jean espérait ainsi légitimer un type d'opérations et un but qui étaient en réalité ceux de l'art qui était à la fois la matrice du Liber florum celestis doctrine et le point d'origine de sa chute, à savoir l'Ars notoria ${ }^{21}$. Cette tradition de magie angélique promettant illumination et connaissance, attestée depuis la fin du XII ${ }^{\mathrm{e}}$ siècle et condamnée par plusieurs théologiens au XIII ${ }^{\mathrm{e}}$ (dont Thomas d'Aquin), était très diffusée dans le monde des écoles ${ }^{22}$. Jean affirme en avoir obtenu une version sur le conseil d'un médecin lombard, un certain Jacques de Bologne ${ }^{23}$; il espérait ainsi pouvoir bénéficier de la doctrina subitanea alors qu'il était trop pauvre pour pouvoir s'acheter tous les livres nécessaires à ses longues études. Évidemment, l'art en question, bien qu'efficace, apparaît vite comme une porte d'entrée le menant subrepticement en Enfer. Jean, se sentant trompé, va dès lors, à la manière de Théophile ${ }^{24}$, faire pénitence du pacte diabolique contracté

19. Ibid., Prologue général, p. 154-155. La chronologie de la rédaction elle-même a été reconstruite par les éditeurs. Voir notamment p. 134-137.

20. Ibid.,p. 155 : «Quecumque enim in hoc libro scripta sunt, donec canonizata fuerint, inter apocrifa fidei discernimus. »

21. Le titre lui-même, Liber florum celestis doctrine, est un emprunt à la tradition de l'Ars notoria. Cf. J. VÉRONÈSE, L'Ars notoria au Moyen Âge. Introduction et édition critique, Florence, 2007, version A, XIII ${ }^{\mathrm{e}}$ s., $\$ 38$ : «Ipsius orationis exemplar Librum florum doctrine celestis Salomon appellavit. »

22. J. VÉRONÈSE, «The Ars notoria in the Middle Ages and Modern Times : Diffusion and Influence(s) », dans S. RAPISARDA et E. NIBLAEUS éd., Dialogues among Books in Medieval Western Magic and Divination, Florence, 2014, p. 147-178. Cette tradition qui inclut plusieurs versions est recensée actuellement pour le seul Moyen Âge dans trenteneuf manuscrits. À la liste établie dans cet article (37 ms, p. 175-176), il convient désormais d'ajouter deux copies de la version glosée (B) : Paris, BnF, ms. nouv. acq. lat. 1565 (XIV s.), que nous avons repéré ; Düsseldorf, Universitäts- und Landesbibliothek, K07 : 073 (XV s.), identifié par László Sándor Chardonnens.

23. JOHN OF MORIGNY, Liber florum celestis doctrine..., p. 158.

24. Ibid., Prologue général, p. 154. 
(un pacte que l'on pourrait qualifier de tacite pour reprendre la typologie thomiste), être sauvé par la Vierge, sans renoncer toutefois à forger un art de la connaissance efficace et licite, capable de mener aux secrets célestes et au salut. Bien qu'il expurge l'Ars notoria de ses éléments les plus compromettants (verba mystica et autres figurae/notae mystérieuses, et donc suspectes), le stratagème ne trompe finalement pas les théologiens, notamment ceux de l'université de Paris, qui condamnent le texte comme succédané de l'Ars notoria en 1323.

La chute initiale de Jean, fruit de son désir de savoir et de sa curiosité, est l'objet d'une relation saisissante, qui raconte par le menu les assauts répétés des démons alors que le moine-étudiant met en pratique les enseignements de l'Ars notoria (avant cela il possédait déjà, apprend-on, un livre de nigromancie, autrement dit un livre de magie rituelle expressément adressée aux démons ${ }^{25}$ ). Les esprits malins, ici, avancent masqués. Le livre de l'Ars notoria, par lequel ils trompent Jean et d'autres (notamment sa sœur Brigitte et un cistercien de sa connaissance, Jean de Fontainejean), a lui-même toutes les apparences de la sainteté et de l'orthodoxie ${ }^{26}$. Surtout, sa mise en pratique, combinant ascèse et prière, s'accompagne de visions (visiones) qui, dans un premier temps, ne laissent nullement présager une quelconque immixtion des démons. Les apparitions ont en général lieu la nuit alors que Jean est dans sa chambre, parfois dans son lit, dans un état intermédiaire de conscience qui confine à l'extase (quasi in excessu mentis; quasi in extasi ; in extasim), tout en restant proche du sommeil et du songe (cum excitatus fuissem; statim evigilavi; continuo excitatus). L'une d'entre elles intervient au terme d'un premier mois d'intense préparation, alors qu'il vient de se coucher après avoir récité « une oraison [...] que l'on appelle Signe de la Grâce », repérable de fait dans la tradition en question ${ }^{27}$. Dans sa chambre soudain baignée de lumière apparaissent tout d'abord deux hommes, que Jean peut voir mais non reconnaître, puis bientôt un troisième, dont le bénédictin ne peut que sentir la présence. Les deux premiers se postent autour de son lit. Celui qui jouit de la plus haute autorité prend alors la parole et fustige la naïveté

25. Ibid., I.i.2, p. 158 ; C. FANGER, «Libri nigromantici. The Good, the Bad, and the Ambiguous in John of Morigny's Flowers of the Heavenly Teaching », Magic, Ritual, and Witchcraft, 7/2 (2012), p. 164-189.

26. Ibid., I.i.3, p. 158-159 : «Qualiter Ars notoria intus et extra fallacissime est contexta et fabricata. Liber enim ille, scilicet Ars notoria, prima facie, scilicet exterius, apparet quod sit omnium librorum pulcherrimus et utilissimus et eciam sanctissimus, quia in eo scriptura debet de diversis coloribus scribi. In eo sunt pulcherrime figure diversis coloribus colorate. Brevissimus liber est, et omnium scienciarum scripturarum et arcium adepcionem brevi tempore Deus omnipotens per ipsum operantibus promittit et tribuit. In ipso sunt oraciones sancte et mirabiles, et figure quarum misterium, ut in ipso dicitur, magis miraculum est quam assuete erudicionis exemplar. $\mathrm{O}$ astucia serpentis antiqui ! [...]. »

27. J. VÉRONÈSE, L’Ars notoria au Moyen Âge..., version A, § 43, p. 49. 
de Jean, qui croyait pouvoir parvenir à ses fins en moins de trente jours quand, lui dit-il, il faut prier pendant au moins quatre-vingts jours. Quant au second, il se contente de confirmer les dires du premier intervenant qu'il nomme « père ». Jean croit alors bénéficier d'une apparition de la Trinité qui lui réclame davantage d'efforts et de patience. Avant que la vision ne se dissipe, le second interlocuteur, que Jean pense désormais être le Fils, lui annonce toutefois qu'il aura une nouvelle vision dans huit jours. Ainsi édifié, Jean reprend aussitôt de manière assidue la pratique de l'Ars notoria, dont le caractère divin paraît indubitable. Ce n'est que plus tard, avoue-til, qu'il devait se rendre compte que toute cette mise en scène n'était en fait qu'une ruse du diable in angelum lucis visant à précipiter sa chute ${ }^{28}$. D'autres visions, dont on peine à démêler la chronologie, viennent en effet progressivement dévoiler l'imposture. C'est le cas, notamment, lorsqu'un homme «superbe, grand, arrogant et dédaigneux » entre un soir par la fenêtre de sa chambre. Il se met à tourner autour de son lit et lui enjoint, si ce dernier entend bien obtenir les dons intellectuels qu'il espère, de l' « adorer et de lui faire hommage ». Jean, qui flaire le danger, refuse. Entrent alors dans sa chambre deux autres personnages qui portent l'habit franciscain ; ils réitèrent l'injonction du premier, qu'ils appellent dominus, mais Jean refuse de nouveau d'obtempérer. Le premier intervenant tente alors une dernière manœuvre pour intimider le moine : il menace de le tuer en lui versant du plomb fondu dans la bouche ! Mais Jean s'entête et dit préférer la mort plutôt que de céder à celui qu'il croit désormais être le diable, sans toutefois en être certain. C'est à ce moment critique qu'une dernière ruse a raison de lui. Croyant être à l'abri des regards indiscrets dans sa chambre, Jean constate soudain qu'un autre « frère mineur », assis sur un banc près de la porte de la pièce, a entendu et vu toute la scène. Ne se rendant pas compte qu'il s'agit d'une nouvelle illusion, Jean croit alors que son secret va être dévoilé. Les deux acolytes du dominus profitent de sa confusion pour le convaincre de prêter hommage à ce dernier. Ils lui enseignent même la procédure à suivre. Bien que le moine doute toujours de la qualité du « seigneur » auquel il s'adresse, il décide, effrayé, de faire profil bas en se « commandant» à lui, tout en priant de ne rien faire de la sorte qui serait contraire au Christ et à la foi ${ }^{29}$. Le pacte de soumission a donc lieu, mais il est obtenu sous la contrainte et se trouve quasi invalidé par l'invocation au Christ (contrairement au modèle théophilien). En dépit de ses doutes qui confinent désormais à la certitude quant à la nature des apparitions, Jean, aiguillonné par son désir, poursuit son étude et sa pratique de l'Ars notoria. Des visions lui permettent même d'approfondir sa connaissance et sa maîtrise de la «nigromancie ». Une nuit toutefois, il est le protagoniste

28. JOHN OF MORIGNY, Liber florum celestis doctrine..., I.i.7, p. 161-162.

29. Ibid., I.i.8, p. 162-163. 
d'une scène décisive dont on ne sait si elle s'inscrit toute entière dans une vision ou si elle est en partie fondée sur des faits présentés comme réels. Lui apparaît un esprit malin déguisé en chérubin (mais vêtu de noir), qui le moleste et le pousse dans les escaliers, avant qu'un autre démon ne finisse par se saisir de lui et ne menace de le tuer, sans doute pour le contraindre à se soumettre cette fois de son plein consentement, c'est-à-dire sans invoquer le nom de Dieu. Pour lui échapper, Jean se fond dans une foule et se rend chez l'évêque pour confesser ses péchés. Il va ensuite à l'église et, tandis qu'il se prosterne devant l'effigie de la Vierge, une voix lui murmure soudain à quel point il a été stupide. Alors qu'il se réveille, ses doutes sur la malignité de l'Ars notoria sont désormais en tout point confirmés ; mais Jean hésite encore à délaisser entièrement l'étude d'un art qui promet des bénéfices auxquels il a déjà goûté ${ }^{30}$. Ce n'est finalement qu'après une ultime vision qu'il décide d'abandonner définitivement cette pratique ${ }^{31}$; mais, à ce point de son parcours, ce n'est encore que pour retomber temporairement dans la très condamnable pratique de la «nigromancie ${ }^{32} »$. Le discernement réclame pour le moins de réprimer entièrement ses désirs. La véritable rédemption n'a lieu que plus tard, notamment lorsque la Vierge autorise enfin Jean à composer sous sa protection le livre qui va lui permettre de satisfaire ses aspirations à l'élévation intellectuelle sans péril pour son salut.

Jean de Morigny, du fait de son goût pour les arts magiques, est donc victime, dans le cadre de visions où se mêlent indistinctement illusion et réalité, d'une forme d'obsession démoniaque qui n'a d'autre but que de lui faire conclure un pacte explicite avec le démon, et donc d'apostasier sa foi ; la victoire de la Vierge et celle du moine pénitent n'en apparaissent en retour que plus éclatantes et exemplaires. Ermine de Reims, quelques décennies plus tard, est elle aussi le jouet de la perversion des démons. Mais dans son cas, l'obsession prend un tour beaucoup plus réaliste et physique, puisque les démons sont les agents d'une mise à l'épreuve qui se rapproche d'une forme de martyre. La contrepartie positive est que son charisme de discernement n'en apparaît que plus affirmé.

Arrivée à Reims en 1384 au moment où son mari n'est plus en capacité de travailler leur terre de Lucheux (en Vermandois), veuve en 1393, Ermine se place sous la protection des chanoines de Saint-Paul du Val-desÉcoliers, en la personne du sous-prieur Jacques Le Graveur. Jusqu'à sa mort de la peste le 25 août 1396, cette femme, très pieuse, est logée dans une chambre attenante au prieuré, donnant notamment sur la cour. Encadrée à la fois matériellement et spirituellement par son confesseur, lui ayant même voué obéissance, elle va être en ce lieu sujette aux «visions »- la première 
entrée date du 31 octobre 1395 - dont Jean rend compte en français peu de temps après sa mort, soit quelques mois plus tard seulement. Le texte, rédigé à la manière d'un journal agrémenté de dialogues, a été édité il y a déjà une vingtaine d'années ; mais l'étude qu'il méritait vient tout juste de lui être consacrée ${ }^{33}$. Pour Jean Le Graveur, il s'agit avant tout de montrer, par un cas limite, la multitude des moyens mis en œuvre par le diable et les démons pour faire chuter une chrétienne peu éduquée, et d'illustrer dans quelles conditions celle-ci peut gagner chaque jour cette lutte sans fin et assurer son salut. Pauvre, pénitente, Ermine se livre à la prière de manière quasi continue, en utilisant un rosaire et une tablette ornée des arma Christi, support à la méditation autour de la Passion et arme hautement démonifuge. Aspirant à recevoir fréquemment la communion, elle se prépare par une ascèse sévère et de lourdes mortifications corporelles que son confesseur tente de modérer. Si elle finit par obtenir quelques visions consolatrices qui lui font expérimenter le divin et sa musique céleste, son expérience relève davantage du martyre spirituel, tant elle est affligée, tentée et battue continument par des démons qui apparaissent sous forme monstrueuse, animale, et, plus pervers, sous celle de saints de l'Église (Augustin, Nicolas, Marie Madeleine, Pierre, Paul le Simple). Ces apparitions illustrent mieux que chez Jean de Morigny la corporéité dont peuvent se prévaloir les démons dans la croyance commune. Pour essayer de la corrompre, ceux-ci se livrent à des orgies ou à des exhibitions sexuelles auprès d'elle la nuit ; ils la frappent, poursuivant ainsi sur un autre mode l'œuvre de mortification du corps entreprise par Ermine elle-même, ou encore lui parlent, parfois dans un langage connu d'eux seuls, marque de leur altérité. Ils peuvent même la transporter dans les airs et la déposer sur le toit de l'église du prieuré $^{34}$. Inébranlable dans sa foi et dans la confiance qu'elle voue à son confesseur, Ermine expérimente chaque jour ou presque, avec succès, le charisme du discernement des esprits, notamment lorsqu'elle est confrontée à l'apparition de ces faux saints qui veulent l'induire en erreur ${ }^{35}$. Fait notable, les émotions jouent en la matière un rôle important, à la manière d'un sixième sens, notamment le degré de peur qu'elle éprouve au moment où les manifestations se produisent dans sa chambre.

Cette présence réelle des démons n'a guère d'équivalent dans ce type de littérature, et Ermine apparaît, pourrait-on dire, comme une démonologue malgré elle. Cela témoigne en cette fin de XIV siècle de la croyance en une matérialité accrue de la manifestation des démons, qui,

33. Jean Le GraVeur, Entre Dieu et Satan. Les visions d'Ermine de Reims († 1396), éd. C. Arnaud-Gillet, Florence, 1997 ; R. BlumEnFEld-Kosinski, The Strange Case of Ermine de Reims. A Medieval Woman Between Demons and Saints, Philadelphie, 2015.

34. R. Blumenfeld-Kosinski, The Strange Case of Ermine de Reims..., chap. 4, « Ermine and Her Demons », p. 96-126.

35. Ibid., chap. 5, «Ermine and the Discernment of Spirits », p. 127-150. 
sans être nouvelle dans les récits exemplaires, s'accorde désormais avec la théorie des corps assumés promue par les théologiens depuis le XIII ${ }^{\mathrm{e}}$ siècle, notamment Thomas d'Aquin ${ }^{36}$. Quant au vol « réel » dont la sainte femme est la victime, il est appelé à devenir, quelques décennies plus tard, l'un des arguments des démonologues qui veulent défendre la thèse de la réalité du sabbat des sorciers et des sorcières, allant ainsi à l'encontre de la tradition juridique du canon Episcopi ${ }^{37}$. L'œuvre de perversion démoniaque relève d'autant moins de l'illusion en ce temps que, du point de vue d'une Église en proie à la division et aux crises, elle se poursuit par le truchement de corps et d'âmes soumises à Satan, ceux du magicien hérétique dans un premier temps, ceux du sorcier et de sa secte dans un second.

\section{Démonologies scolastiques, démonologiques magiques (XIII ${ }^{\mathrm{e}}-\mathrm{XV}$ e siècles)}

Comme l'a mis en évidence Martine Ostorero dans sa thèse parue en $2011^{38}$, la démonologie scolastique a bénéficié ces dernières années d'un net regain d'intérêt chez les médiévistes, à la suite notamment des travaux d'Alain Boureau ${ }^{39}$ et de Maaike Van der $\operatorname{Lugt}^{40}$. La doctrine, qui se précise dans les dernières décennies du XIII ${ }^{\mathrm{e}}$ siècle, s'articule autour de quelques grands principes, que l'on peut rappeler brièvement : dans la lignée du canon Firmiter du concile de Latran IV (1215) est affirmée la nature « spirituelle » des démons qui sont des substances ou des intelligences « séparées », comme les anges qu'ils ont été avant leur chute ; cantonnés au monde sublunaire, lorsqu'ils ne sont pas au Purgatoire ou en Enfer à tourmenter les âmes, les démons peuvent «assumer» (et non pas créer) un corps élémentaire, simuler par son intermédiaire les opérations corporelles et vitales (manger, parler, etc.), se métamorphoser, entrer en contact physique avec les humains, voire procréer en subtilisant la semence d'un homme ; ils peuvent posséder les corps de l'intérieur, ainsi que l'attestent de longue date le Nouveau Testament et l'hagiographie par la multitude des miracles d'exorcisme ${ }^{41}$, ou encore « incliner » l'esprit humain, par le biais d'illusions qui abusent les sens ou d'une influence exercée sur l'imagination, notamment dans le cadre des rêves, conformément, là encore, à une tradition ancienne ; enfin,

36. Cf. infra.

37. M. OStORERo, Le Diable au sabbat. Littérature démonologique et sorcellerie (14401460), Florence, 2011, p. 619-647.

38. Ibid., p. 219-220.

39. A. Boureau, Satan hérétique...

40. M. VAn DeR Lugt, Le Ver, le démon et la Vierge. Les théories médiévales de la génération extraordinaire, Paris, 2004.

41. ChaVe-MahiR, L'Exorcisme des possédés... 
leur volonté est obstinément mauvaise et ils agissent avec la permission de Dieu, sans pouvoir outrepasser les limites de leur nature ${ }^{42}$.

Fondée sur ces grandes lignes qu'elle a contribué à définir, la démonologie de Thomas d'Aquin († 1274), exposée notamment dans les douze questions De demonibus de la question 16 du De malo (v. 1272), reste l'horizon dominant de l'historiographie. Cela est dû à l'influence générale du maître canonisé en 1323, et surtout au nombre important de « démonologues », souvent inquisiteurs, qui sont issus des rangs dominicains à la fin du Moyen Âge. Tôt s'est posée la question de son influence dans l'émergence de la persécution des sorciers et des sorcières au XV $\mathrm{XV}^{\mathrm{e}}$ siècle. Dans une étude parue en 1940, Charles Edward Hopkin minorait le rôle des conceptions démonologiques de l'Aquinate dans la genèse de la chasse aux sorcières ${ }^{43}$. De fait, Thomas d'Aquin ne dit rien du sabbat en tant que tel, dont l' « imaginaire » est progressivement formalisé à partir des années 1430-1440 chez des auteurs, parfois des juges, provenant d'horizons différents ${ }^{44}$. Toutefois, au-delà de la seule question du sabbat, la question a été depuis lors réévaluée, notamment en prenant pour point de référence le Malleus maleficarum (1487, édition princeps à Spire) de l'inquisiteur dominicain Henri Kramer, l'un des monuments de la démonologie du sabbat et l'un des vecteurs de sa féminisation ${ }^{45}$. Christine Pigné, notamment, a montré comment la démonologie thomiste a contribué, chez Kramer, à élaborer, de manière quelque peu paradoxale, le cadre intellectuel justifiant la constitution de sectes hérétiques de sorciers, et par là-même leur répression ${ }^{46}$ : la puissance limitée accordée aux démons par le docteur angélique et l'affirmation de leur nature spirituelle n'auraient fait qu'accroître la nécessité de leur adjoindre des « instruments » humains efficaces (tels que les sorciers et sorcières liés à eux individuellement et collectivement par un pacte), capables en quelque sorte d'incarner leur pouvoir de subversion ici-bas ${ }^{47}$. Des démons relativement faibles avaient

42. M. Ostorero, Le Diable au sabbat..., p. 220-223.

43. C. E. Hopkin, The Share of Thomas Aquinas...

44. M. Ostorero, A. Paravicini Bagliani, K. Utz Tremp éd., en collab. avec C. CHÈnE, L'Imaginaire du sabbat. Édition critique des textes les plus anciens (1430 c.1440 c.), Lausanne, 1999.

45. A. BOUREAU, «Le sabbat et la question scolastique de la personne », dans N. JACQUESCHAQUin et M. PRÉAUd éd., Le Sabbat des sorciers (XVe-XVIII siècles), Grenoble, 1993, p. 33-46 ; A. SCHNYDER, Malleus Maleficarum von Heinrich Institoris (alias Krämer) unter Mithilfe Jakob Sprengers aufgrund der dämonologischen Tradition zusammengestellt, 2 vol. , Göppingen, 1991-1993 ; H. P. BROEDEL, The Malleus Maleficarum and the Construction of Witchcraft. Theology and Popular Belief, Manchester, 2003.

46. C. PignÉ, « Du De malo au Malleus Maleficarum. Les conséquences de la démonologie thomiste sur le corps de la sorcière », Cahiers de recherches médiévales, 13 (2006), p. 195-220.

47. F. MERCIER, «Membra diaboli. Remarques sur le statut et l'imaginaire du corps sorcier au XV $\mathrm{XV}^{\mathrm{e}}$ siècle », Cahiers de recherches médiévales, 13 (2006), p. 181-193. 
en quelque sorte besoin d'agents dévoués corps et âme et particulièrement maléfiques pour constituer le « corps mystique »de Satan et amoindrir d'autant le royaume de Dieu.

L'autorité de la démonologie de saint Thomas à la fin du Moyen Âge n'a cessé depuis lors d'être mieux évaluée, en même temps que les grands textes démonologiques - notamment ceux formalisant et justifiant la réalité du sabbat et sa nécessaire éradication - étaient l'objet d'études, voire d'éditions. Si des dominicains plus ou moins influents comme Jean Nider, Jean Vinet, Nicolas Jacquier ou Henri Kramer, pour n'en citer que quelques-uns ${ }^{48}$, ont trouvé sans conteste les fondements de leurs théories sur les modes de l'action démoniaque sur les hommes chez la grande autorité de leur ordre, cela ne signifie pas pour autant, en fonction du contexte dans lequel ils ont écrit et de leurs objectifs spécifiques, qu'ils les ont interprétés à l'identique, qu'ils leur ont accordé le même poids, ni même qu'ils se sont contentés de puiser dans les seuls écrits du maître ${ }^{49}$. Du côté des théologiens qui n'étaient pas des frères prêcheurs, la situation apparaît encore plus nuancée : le chanoine de Tournai Jean Tinctor, formé à l'université de Cologne, auteur vers 1465 d'un Traité du crime de vauderie, a ainsi pleinement reçu la doctrine thomiste ${ }^{50}$, quand un démonologue comme Pierre Mamoris, issu de l'université de Poitiers, a davantage été influencé, dans son Flagellum maleficorum (v. 1460), par la tradition franciscaine représentée au XIII ${ }^{\mathrm{e}}$ siècle par Bonaventure, par exemple sur la nature du corps assumé par les démons (il faut toutefois noter qu'il a probablement eu un dominicain parmi ses maîtres en la personne de Guillaume Méry ou Aimery, l'un des examinateurs de Jeanne d'Arc à Poitiers en 1429, et qu'il cite volontiers le docteur angélique parmi les autorités ${ }^{51}$. La théologie thomiste du pacte magico-divinatoire, avec la distinction entre pacte exprès et tacite, a aussi, à n'en pas douter, contribué fortement à assurer la postérité

48. Outre M. Ostorero, Le Diable au sabbat... et dans une moindre mesure Il diavolo nel Medioevo..., voir nombre de contributions à des actes de colloques récents : M. OSTORERO, G. Modestin et K. UTZ TREMP éd., Chasses aux sorcières et démonologie. Entre discours et pratiques (XIVe-XVII siècles), Florence, 2010 ; M. OSTORERO et J. VÉRONÈSE éd., Penser avec les démons. Démonologues et démonologies (XIII ${ }^{e}$-XVII ${ }^{e}$ siècles), Florence, 2015.

49. Voir par exemple M. Ostorero, Le Diable au sabbat..., p. 251-344, à propos des différences notables entre les dominicains, thomistes tout deux, Jean Vinet et Nicolas Jacquier. Vinet est le premier à utiliser massivement les textes de Thomas d'Aquin dans le contexte de la sorcellerie démoniaque (p. 257).

50. JEAN TINCTOR $(\dagger 1469)$, Invectives contre la secte de vauderie, éd. E. VAN Balberghe et F. Duval, Tournai-Louvain-la-Neuve, 1999 ; F. MercIER, La Vauderie d'Arras. Une chasse aux sorcières à l'Automne du Moyen Âge, Rennes, 2006, p. 109-121 ; ID., «"Des choses qui surmontent la puissance des anges". La défense de la toute-puissance divine dans le Traité du crime de vauderie de Jean Tinctor », dans M. OSTORERO et VÉRONÈSE éd., Penser avec les démons..., p. 121-143.

51. M. Ostorero, Le Diable au sabbat..., p. 165-198 et 345-386, notamment p. 365 et 385. 
du docteur angélique sur ce terrain, comme en témoignent quelques traités contre les « invocateurs de démons » et, de manière plus générale, de nombreux textes opposés à la superstition des arts magiques et divinatoires aux derniers siècles du Moyen Âge ${ }^{52}$. Au vu des avancées récentes de l'historiographie sur les sources de première main, une étude globale de cette influence aux $\mathrm{XIV}^{\mathrm{e}}$ et $\mathrm{XV}^{\mathrm{e}}$ siècles (voire au-delà) apparaît désormais envisageable et mériterait d'être entreprise.

Thomas d'Aquin, pour influent qu'il ait été à moyen et long terme, n'a toutefois pas eu l'exclusivité en matière de spéculations démonologiques. Alain Boureau a attiré l'attention, dans Satan hérétique, sur les conceptions démonologiques de la mouvance franciscaine de la fin du XIII ${ }^{\mathrm{e}}$ et du premier XIV ${ }^{\mathrm{e}}$ siècle, notamment du fait que l'un des acteurs essentiels dans le processus de qualification de la magie comme hérésie démonolâtre a été le franciscain Enrico del Carretto (†1323), consulté avec neuf autres experts en 1320 sur ce sujet par le pape Jean XXII suite à un certain nombre d'affaires judiciaires ${ }^{53}$. Le frère mineur a en effet été l'un des deux, parmi les dix interrogés, à défendre sans réserve l'imputation d'hérésie, au prix notamment d'une théologie qui accordait une autonomie plus grande au démon dans l'ordre de la Création, dans la lignée d'une tradition franciscaine

52. À titre d'exemples, on peut citer : le Contra astrologos imperitos atque nigromanticos de Nicolas Eymerich, que nous avons récemment édité : J. VÉRONÈSE, « Le Contra astrologos imperitos atque nigromanticos (1395-1396) de Nicolas Eymerich (O. P.) : contexte de rédaction, classification des arts magiques et divinatoires, édition critique partielle », dans OSTORERo et al. éd., Chasses aux sorcières et démonologie..., p. 271-329; 2 ${ }^{\mathrm{e}}$ partie de l'édition dans Id., « Nicolas Eymerich et l'astrologie à la cour d'Aragon », dans J.-P. BOUDET, M. Ostorero et A. PARAVICIni Bagliani éd., De Frédéric II à Rodolphe II. Astrologie, divination et magie dans les cours (XIII ${ }^{e}$-XVII siècle), Florence, 2017, p. 97-155; ou encore le De superstitionibus que rédige en 1405 le réformateur Nicolas de Jauer alors qu'il est maître en théologie à l'université d'Heidelberg. Le texte, largement fondé sur Thomas d'Aquin, a connu un immense succès au $\mathrm{XV}^{\mathrm{e}} \mathrm{s}$. puisqu'il est recensé dans plus de cent quarante manuscrits. $C f$. K. BRACHA, Des Teufels Lug und Trug. Nikolaus Magni von Jauer : Ein Reformtheologe des Spätsmittelalters gegen Aberglaube und Götzendienst, Dettelbach, 2013. De manière plus générale sur cette question, $c f$. M. D. BAILEY, Fearful Spirits, Reasoned Follies. The Boundaries of Superstition in Late Medieval Europe, Ithaca-Londres, 2013.

53. A. BoureAu, Le Pape et les sorciers. Une consultation de Jean XXII sur la magie en 1320 (manuscrit B.A.V. Borghese 348), Rome, 2004 ; ID., Satan hérétique..., p. 31-64. Sur quelques affaires, voir notamment : E. ALBE, Autour de Jean XXII. Hugues Géraud, évêque de Cahors, Cahors, 1904, p. 40-67 ; R. MiCHEL, « Le procès de Matteo et de Galeazzo Visconti. L'accusation de sorcellerie et d'hérésie. Dante et l'affaire de l'envoûtement (1320) », École française de Rome. Mélanges d'archéologie et d'histoire, 20 (1909), p. 269327 ; F. Bock, « I Processi di Giovanni XXII contro i Ghibellini delle Marche », Bulletino dell'Istituto storico italiano per il Medio Evo e archivio Muratoriano, 57 (1941), p. 19-70 ; J.-P. BOUDET et J. THÉRY, « Le procès de Jean XXII contre l'archevêque d'Aix Robert de Mauvoisin (1317-1318) : astrologie, arts prohibés et politique », dans Jean XXII et le Midi, Cahiers de Fanjeaux, 45 (2012), p. 159-236. 
qui s'était construite en partie en réaction aux positions thomistes ${ }^{54}$. Si le dominicain tendait, en calquant sa démonologie sur un modèle angélique « surhumain », à limiter les possibilités d'intervention des démons dans le monde terrestre (en dépit de la théorie des corps assumés), ses contradicteurs proposaient au contraire une doctrine qui laissait aux esprits mauvais, y compris dans l'économie de la chute, l'usage d'une volonté forte, susceptible de renforcer leur capacité contractante et leur proximité avec les humains. Dans cette lignée, Enrico del Carretto, en élevant les rituels magiques - et notamment l'utilisation d'images d'envoûtement baptisées - au rang de quasi-sacrement satanique, tendait à attribuer au diable une puissance qui n'était plus strictement confinée à l'ordre naturel, ou qui menaçait du moins de ne plus l'être. Pour lui, l'image, signe institué par les démons, devient efficace quand le magicien ou le sorcier intervient par des invocations et des actes (notamment l'utilisation d'eau bénite) engageant sa volonté et sa foi. Le fait de consacrer s'avère décisif, car il sépare l'image de son statut naturel et la transforme en signe «performatif ». Cette construction constitue la face obscure d'une conception contractuelle des sacrements ébauchée dès les années 1230 par l'évêque de Paris Guillaume d'Auvergne, développée ensuite par les franciscains Bonaventure et Pierre de Jean Olivi, et opposée à la conception ministérielle, hiérarchique et instrumentale de l'efficacité sacramentelle défendue notamment par Thomas d'Aquin ${ }^{55}$. Du pacte magique et maléfique traditionnel revu par Thomas d'Aquin au contrat quasi sacramentel avec les démons tel que défini par Enrico del Carretto, il y avait une avancée notable, pour le moins inquiétante sur le plan ecclésiologique et eschatologique, capable de pousser le pape à changer de paradigme juridique vis-à-vis de pratiques magiques et maléfiques qui n'avaient jusque-là, au pis, que « saveur d'hérésie » (selon la formulation d'Alexandre IV dans la bulle Accusatus de 1258), mais qui étaient en général reléguées dans la catégorie des simples « superstitions ${ }^{56}$.

Aussi importante soit-elle sur le plan doctrinal, on peut toutefois se demander jusqu'à quel point cette argumentation a eu une influence

54. A. Boureau, Satan hérétique..., p. 148-156 ; PIERRE DE JEAn Olivi, Traités des démons, Summa, II, Questions 40-48, éd. A. BoureaU, Paris, 2011 ; Richard DE MediaVILla, Questions disputées, t. IV, Questions 23-31, Les démons, éd. A. BourEAU, Paris, 2011.

55. A. Boureau, Satan hérétique..., p. 82-86 et 148-157 ; I. RoSIER-CATACH, La Parole efficace. Signe, rituel, sacré, Paris, 2004, chap. 2 : «Les débats sur le mode d'efficacité des sacrements », p. 99-184 ; EAD., « Signes sacramentels et signes magiques : Guillaume d'Auvergne et la théorie du pacte », dans F. Morenzoni et J.-Y. TilliEtTE éd., Autour de Guillaume d'Auvergne († 1249), Turnhout, 2005, p. 93-116.

56. J. HANSEN, Quellen und Untersuchungen zur Geschichte des Hexenwahns und der Hexenverfolgung im Mittelalter, Bonn, 1901, réimpr. Hildesheim, 1963, p. 1. Le texte a été intégré au corpus de droit canon par Boniface VIII (Sextus) : Corpus iuris canonici, éd. E. FRIEDBERG, Leipzig, 1879-1881, 2, col. 1071-1072. 
et une postérité. Au vu de la bulle Super illius specula (1326-1327) conservée dans le Directorium inquisitorum (1376) de Nicolas Eymerich ${ }^{57}$, Jean XXII a fini par conclure que les magiciens démonolâtres étaient bel et bien des hérétiques. Toutefois, comme l'a remarqué Isabel Irribaren ${ }^{58}$, si l'on en croit notamment le nombre d'annotations de la main même du pape présentes dans le manuscrit du Vatican qui conserve la consultation de 1320, il semble que celui-ci a été moins intéressé par les réflexions théologiques du franciscain que par les réponses apportées par le carme Guido Terreni $(† 1342)$, le second à avoir approuvé pleinement l'imputation d'hérésie ${ }^{59}$. Refusant les audaces d'une doctrine libérant les démons, souscrivant à la conception instrumentale des sacrements, le Catalan, par ailleurs farouche promoteur de la souveraineté pontificale et adversaire patenté de la mouvance spirituelle franciscaine se réclamant notamment d'Olivi ${ }^{60}$, a avant tout déployé des arguments de nature ecclésiologique et juridique pour asseoir sa conclusion ${ }^{61}$. Qu'elle qu'ait pu être son influence sur le pape, sa réponse montre en tout cas que l'imputation d'hérésie concernant les « invocateurs de démons » ne dépendait pas nécessairement de la mobilisation d'une démonologie « libératrice » ou de la promotion d'un pacte démoniaque «fort». Cela se vérifie du reste ultérieurement, par exemple chez l'inquisiteur dominicain Nicolas Eymerich, qui reste fidèle à Thomas d'Aquin en matière démonologique, mais se range, en juge dévoué à la défense de la foi et de l'autorité de l'Église, parmi les ardents défenseurs de la qualification de la magie comme hérésie, en reprenant à son compte les arguments de son compatriote Guido Terreni (qui lui aussi a été inquisiteur de la foi ${ }^{62}$. Cela semble rejoindre la démonstration de Christine Pigné sur le fait que la démonologie limitative (et opposée à toute tentation dualiste) de Thomas a moins entravé qu'elle n'a peut-être favorisé la justification de l'existence de sectes de malefici liés au « corps » du diable, comme autant de membres, par le rituel d'hommage du sabbat.

57. Directorium inquisitorum Nicolai Eymerici, Rome, 1578, II pars, quasstio XLIII, De invocantibus damones, p. 239-240 ; J. HANSEN, Quellen und Untersuchungen..., p. 5 ; M. OSTORERO, Le Diable au sabbat..., p. 236-237.

58. I. IRIBARREN, «From Black Magic to Heresy : a Doctrinal Leap in the Pontificate of John XXII », Church History, 76 (2007), p. 32-60 ; R. KIECKHEFER, «Witchcraft, Necromancy and Sorcery as Heresy », dans M. OSTORERO et al. éd., Chasses aux sorcières et démonologie..., p. 133-153, ici p. 144.

59. A. Boureau, Le Pape et les sorciers..., p. 43-85 (édition de la réponse de Terreni).

60. A. Boureau, Satan hérétique..., p. 66-67 ; A. FidOra éd., Guido Terreni, O. Carm. $(†$ 1342). Studies and Texts, Turnhout, 2015.

61. Pour une analyse détaillée, $c f$. I. IRIBARREN, « From Black Magic to Heresy... ».

62. J. VÉRONÈSE, « Nigromancie et hérésie : le De jurisdictione inquisitorum in et contra christianos demones invocantes de Nicolas Eymerich (O. P.) », dans M. OSTORERO et J. VÉRONÈSE éd., Penser avec les démons..., p. 5-56 (p. 36-42). 
La théologie scolastique n'a pas été la seule à avoir professé un intérêt pour les démons aux derniers siècles du Moyen Âge. La littérature magique - notamment par le biais d'un certain nombre de textes de magie rituelle - a elle aussi livré sur ce sujet un savoir, qui relevait toutefois davantage de l'imaginaire et de la représentation que de la spéculation, $\mathrm{au}$ contenu par ailleurs très hétérogène et variable d'un texte à l'autre, et qui ne s'accordait en outre que très partiellement avec l'orthodoxie chrétienne. Ces démonologies alternatives circulaient au premier chef dans les «catalogues de démons » que Jean-Patrice Boudet a entrepris d'étudier et dont l'édition d'un certain nombre de versions attribuées à Salomon ou à saint Cyprien, le magicien repenti, est en cours ${ }^{63}$. Ces textes ne livrent aucune procédure ritualisée de conjuration, mais révèlent au conjurateur les noms et le pedigree des démons qu'il va pouvoir solliciter à l'aide d'autres formulaires pour parvenir à une fin précise. Parmi eux, on peut mentionner le De officiis spirituum, dont une version du $\mathrm{XV}^{\mathrm{e}}$ siècle est conservée dans l'une des plus importantes collections de magie salomonienne qui nous soit parvenue ${ }^{64}$. Ce texte affirme le principe de la malignité des démons et le fait qu'ils ont chuté, après Lucifer, des neuf ordres angéliques auxquels ils ont appartenu, avant d'être cantonnés dans le monde sublunaire et en enfer ${ }^{65}$; il évoque encore au côté de Lucifer des démons bibliques comme Belzébuth, Satan, Bélial ou Asmoday ${ }^{66}$, et semble affirmer leur nature spirituelle, puisque les démons, qualifiés souvent de spiritus, doivent assumer un corps aérien pour se présenter devant le conjurateur/exorciste ${ }^{67}$. De manière générale, ces mauvais esprits ont une apparence monstrueuse qui témoigne de leur péché. Dans la pratique néanmoins, les démons ne produisent pas systématiquement le mal au profit du magicien, qui n'apparaîtrait dès lors, si tel était le cas, que comme un vulgaire maleficus; avec la permission de

63. J.-P. BoudET, « Les who's who démonologiques de la Renaissance et leurs ancêtres médiévaux », Médiévales, 44 (2003), p. 117-139 ; J.-P. BouDET, Entre science et nigromance..., p. 375-383 ; M. OsTORERo, Le Diable au sabbat..., p. 242-249. L'édition des catalogues de démons par Jean-Patrice Boudet est prévue à la Micrologus' Library, Sismel, dans la série Salomon Latinus.

64. Ms. Coxe 25 (collection privée), ex Amsterdam, BPH, 114, XV s. (origine germanique), p. 173-187.

65. Ibid., p. 174 : «Primus angelus quam fuit Lucifer qui fuit sapientior et splendidior et sapientior cunctis, ut quidam dicunt, quod de eadem natura fuit creatus quam boni angeli, id est de incorruptibili materia, sed non per plenam horam stetit in preclaro pallatio, quia mox superbiendo cecidit cum omnibus suis, et ideo cecidit cum omnibus suis complicibus, et ideo cecidit cum videret omnes ordines angelorum gloria et honore excellere confusus in furorem. » [transcription de J.-P. Boudet].

66. P. A. Almond, The Devil. A New Biography, Londres/New York, 2014, p. 23.

67. Ms. Coxe 25, p. 175-176: «Veram etiam omnes spiritus infernales et aeree potestates abhorrent et nequeunt venire quando nebulosum est tempus, idcirco quia spiritus carnem et ossa non habent, cum anima exeunt de locis suis et apparent exorcisti possunt aerea corpora sibi assumere [...]. » 
Dieu, ils assouvissent au contraire l'ensemble de ses désirs, majoritairement orientés dans ce cas vers la connaissance de l'avenir ou des choses cachées, voire la maîtrise des arts du cursus universitaire, ou bien lui apportent leur aide ou leur protection en différents domaines (don d'argent, d'honneurs, guérison, etc.). Cela rejoint plus généralement le fait que, dans nombre d'experimenta, les démons convoqués ne sont pas forcément considérés comme mauvais, voire résolument et définitivement exclus de la rémission des péchés et du salut ${ }^{68}$, ce qui se retrouve comme contraire à la foi dans la condamnation de la magie élaborée par la Faculté de théologie de l'université de Paris en 1398, suite à l'affaire du magicien Jean de Bar ${ }^{69}$. Même si Lucifer semble avoir une certaine préséance au vu de la crainte qu'il inspire à ses coreligionnaires ${ }^{70}$, le De officiis spirituum livre l'image d'une multitude démoniaque partiellement hiérarchisée sous l'autorité de rois, de princes, de ducs, de comtes ou de marquis qui, sans véritablement établir de hiérarchie entre eux, gouvernent chacun un nombre variable de légions, qui n'est pas du reste corrélé à l'importance de la fonction ou du titre. Parmi eux figure notamment Bileth, un roi auquel est par ailleurs dédié un livre entier conservé dans un autre manuscrit du $\mathrm{XV}^{\mathrm{e}}$ siècle, où il apparaît à la manière d'un prince oriental ${ }^{71}$.

$\mathrm{Si}$, du fait de défaut de hiérarchie, on ne leur associe guère dans le De officiis spirituum le capital symbolique d'une majesté à même de les rendre inquiétants, celle-ci est parfois magnifiée, comme par exemple dans le Liber angelicus conservé dans le même manuscrit ${ }^{72}$. Appelé également Liber occultus ou Liber miraculorum, ce livre détenteur « des secrets des secrets » permet de contraindre les anges déchus. Mais, contrairement à

68. R. KIECKHEFER, Forbidden Rites. A Necromancer's Manual of the Fifteenth Century, Stroud, 1997, p. 154-169.

69. J.-P. BOUDET, « Les condamnations de la magie à Paris en 1398 », Revue Mabillon, n.s. 12, 73 (2001), p. 121-157, ici p. 151 : «Vicesimus tertius articulus : quod aliqui demones boni sint, alii benigni, alii omniscientes, alii nec salvati nec damnari. Error. » Signalons la parution prochaine d'un article important sur les affaires de magie sous le règne de Charles VI : J.-P. Boudet et J. ChIFFOLEAU, « Magie et construction de la souveraineté sous le règne de Charles VI », dans J.-P. Boudet et al. éd., De Frédéric II à Rodolphe II. Astrologie, divination et magie dans les cours...

70. Ms. Coxe 25, p. 174 : « Si vero de legionibus suis scire volueris, nobis est valde obscurum, quia omnes maligni spiritus sive angeli ipsum timent et obediunt ei. »

71. J.-P. BOUDET, « La magie au carrefour des cultures dans la Florence du Quattrocento : le Liber Bileth et sa démonologie », dans M. OSTORERO et J. VÉRONÈSE éd., Penser avec les démons..., p. 313-344, avec l'édition du texte conservé dans le ms. Florence, BNC, II.iii.214, fol. $78 \mathrm{v}-84 \mathrm{r}$.

72. Ms. Coxe 25, p. 3-40. Nous avons présenté récemment ce texte et sa transcription dans le cadre d'une communication intitulée : «Le manuscrit Coxe 25, un témoin capital des traditions de magie salomonienne », Journée d'étude Les sciences dites " occultes » à la fin du Moyen Âge et à l'époque moderne : autour des livres précieux de la collection Coxe, organisée par J.-P. Boudet, F. Coxe et J. Véronèse, Ouchamps, 4 novembre 2016. 
la doctrine de l'Église, ces maligni spiritus n'ont pas tous été expulsés du ciel, puisque certains sont restés au service des signes du zodiaque, des mansions lunaires ou encore des planètes. Des souverains démoniaques et leurs serviteurs peuplent donc les sphères. Tous sont par ailleurs soumis à un chef suprême, un certain Mirezin (non attesté à notre connaissance dans les catalogues de démons conservés, ni du reste dans les autres textes et experimenta de magie rituelle, excepté dans la Summa sacre magice du Catalan Bérenger Ganell ${ }^{73}$ ), qui trône couronné, en majesté, au « milieu du ciel » (dans la sphère aérienne semble-t-il néanmoins, plutôt que dans la sphère du Soleil, ce qui aurait eu une portée symbolique supérieure), entouré de la cour de ses vassaux, empereurs et rois en tête ${ }^{74}$. En ce monde, Mirezin a des messagers efficaces, notamment les démons des points cardinaux Oriens, Egin, Paymon et Amaymon, qui gouvernent la multitude démoniaque. Est ainsi mise en place toute une société démoniaque bien ordonnée, qui semble régenter quotidiennement la machine du monde sous l'autorité tyrannique de son maximus imperator et potentissimus ${ }^{75}$, et qui ne peut être ponctuellement dominée que par le conjurateur en vertu de l'infinie puissance de Dieu, pour faire le mal comme le bien ${ }^{76}$. On perçoit ici comment de tels textes, qui circulaient dans les milieux cléricaux et curiaux au moment même où nombre de magiciens et de sorciers étaient pourchassés pour hérésie par les tribunaux ecclésiastiques ou séculiers, ont pu apparaître comme « un véritable défi [...] à l'égard des autorités de l'Église et de l'État ${ }^{77} »$.

73. Ms. Kassel, Univ. Bibl., $4^{\circ}$ astron. 3 , fol. $75 \mathrm{v}$, Summa sacre magice, III, 1, ch. 3. Cette source exceptionnelle date de 1346.

74. Ms. Coxe 25, p. 6-7 : « Isti sunt omnes reges et imperatores, sunt antigradi et vicarii et pares curie et consiliatores sunt omnes demones et malignos spiritus Merezin qui sedet in medio celi centro aerei in sua sede fabricata lapidibus preciosis et auro compositam et coronam auream habentis in capite suo, et omnes isti reges et imperatores ante eum stant, et omnes isti eum adorant et collaudant cavendo et consiliando eum, et omnes alii sunt cursores qui vadunt et recedunt et istis regibus et imperatoribus racionem reddunt de omnibus aliis operibus que committunt in hoc mundo facere. [...]. Sed isti suprascripti reges et imperatores sunt judices addandum judicium in illos qui jussi sunt a Mirezin in hoc mundo. Et sunt nomina illorum cursorum : primus vocatur Oriens, secundus Amaymon, tercius Paimon, quartus Egin et illorum malicia secundum quod legi in Libro eutentico [i.e. la tradition attestée par ailleurs de l'Ydea Salomonis] istis quatuor cursores sunt dispersi in quatuor mundi partibus cum omnibus suis, scilicet in oriente, in occidente, in meridie et in septentrione. »

75. Ibid., p. 26.

76. Ibid., p. 3-4.

77. J.-P. BOUDET, Entre science et nigromance..., p. 383. 


\section{L'hérésie des sorciers et les pouvoirs}

L'historiographie de la chasse aux sorciers et aux sorcières au $\mathrm{XV}^{\mathrm{e}}$ siècle a été principalement marquée ces dernières années par les travaux de l'école de Lausanne (sous la direction d'Agostino Paravicini Bagliani), qui ont institué un retour salutaire aux textes, aussi bien pour ceux qui rendent compte ou participent à l'émergence du sabbat, que pour les actes de procès attentés à des sorciers, qui eux aussi attestent sa diffusion. Dans le premier domaine, L'Imaginaire du sabbat, en présentant les cinq textes les plus anciens (1428-1442) qui mentionnent de manière plus ou moins cohérente et aboutie le célèbre rituel et dessinent une première géographie du sabbat ancrée dans l'arc alpin (val d'Aoste, territoire de Berne, diocèse de Lausanne, Valais et vallées du Dauphiné) ${ }^{78}$, a eu un rôle précurseur, qui a appelé par la suite d'autres travaux que l'on pourrait qualifier de « démonologie pure », tels ceux que Martine Ostorero a consacrés aux démonologues français du milieu du XV $\mathrm{XV}^{\mathrm{e}}$ siècle Jean Vinet, Nicolas Jacquier et Pierre Mamoris ${ }^{79}$. Du côté judiciaire, ont été publiés et analysés, en lien avec les textes théoriques ou littéraires, l'ensemble des actes de procédure du registre Ac 29 des archives cantonales vaudoises, qui conserve des procès pour hérésie contre des sorciers sur une période de presque un siècle $(1438-1528)^{80}$. Au-delà de l'imaginaire du sabbat qui apparaît dans les procès-verbaux, sont ainsi mis au jour les formes procédurales, les personnels judiciaires (notamment les inquisiteurs), les inculpés, hommes et femmes ; l'on est notamment frappé par la diversité des profils socioéconomiques de ces derniers et par la variété des enjeux qui se cachent derrière l'accusation d'hérésie. Dans la même veine, appliquant une méthode éprouvée conjuguant édition-traduction des sources et données micro-historiques, Sophie Simon a exploré la documentation moins fournie

78. M. OSTORERO et al. éd., L'Imaginaire du sabbat... Il s'agit du rapport en allemand du chroniqueur lucernois Hans Fründ, du Formicarius de Jean Nider, des Errores gazariorum (anonyme), du Ut magorum et maleficiorum errores de Claude Tholosan, et du Champion des dames de Martin Le Franc.

79. M. OSTORERO, Le Diable au sabbat...

80. M. Ostorero et K. UtZ TremP éd., en collab. avec G. Modestin, Inquisition et sorcellerie en Suisse romande. Le registre Ac 29 des Archives cantonales vaudoises (14381528), Lausanne, 2007. Ce volume venait clore une série de publications aux Cahiers lausannois d'histoire médiévale : P.-H. CHOFFAT, La Sorcellerie comme exutoire. Tensions et conflits locaux : Dommartin 1524-1525, Lausanne, 1989 ; M. OsTORERO, "Folâtrer avec les démons ». Sabbat et chasse aux sorciers à Vevey (1448), Lausanne, 1995 [nouv. éd. 2008] ; E. MAIER, Trente ans avec le diable. Une nouvelle chasse aux sorciers sur la Riviera lémanique (1477-1484), Lausanne, 1996 ; L. PFISTER, L'Enfer sur terre. Sorcellerie à Dommartin (1498), Lausanne, 1997 ; G. Modestin, Le Diable chez l'évêque. Chasse aux sorciers dans le diocèse de Lausanne (vers 1460), Lausanne, 1999. 
du diocèse de Genève ${ }^{81}$. Elle livre au passage quelques magnifiques cas, comme celui d'une veuve, Rolette de Tupho, originaire de Satigny, contre laquelle une procédure inquisitoire est ouverte le 21 novembre 1497 par le procureur de la foi, le dominicain de Genève Hugues Alexi, assisté d'un vice-inquisiteur, lui aussi dominicain genevois, Jean Guynod ${ }^{82}$. Après sans doute une enquête préliminaire fondée sur la fama publica, l'accusée, de manière classique, subit trois interrogatoires, conclus chacun par une monition l'invitant à la reconnaissance de ses crimes et à la réconciliation. Devant le refus obstiné de livrer des aveux, les juges font appliquer la torture, ce qui pousse finalement Rolette à faire pénitence. La confession elle-même, rendue par le notaire sous forme dialoguée, est haute en couleur et a une valeur quasi exemplaire :

Elle confessa qu'une fois, il y a environ neuf ans, l'accusée reposait au lit avec son mari qui dormait et avant minuit elle était grandement contrariée parce qu'il lui avait été reproché d'être hérétique, et elle se demandait comment se venger de ses ennemis. Alors le diable lui apparut sous l'aspect d'un chien noir en disant : «N'aie pas peur ! Qu'as-tu ? » Auquel elle répondit : «Les gens parlent injustement de moi.» Le diable répondit : «Tais-toi ! Si tu me crois, je les ferai bien taire et te vengerai de tous tes ennemis. Je suis le diable de l'enfer ! » Alors elle-même se leva de son lit et alla au même endroit que lui dans ladite chambre, et dit au diable : «Que veux-tu que je fasse ? » Alors le diable lui dit, parlant d'une voix rauque et difficilement intelligible: «Tu me donneras ton corps et ton âme et tu renieras ton Dieu, sa mère, la foi catholique et le baptême. » Ainsi fit-elle [...].

Un mois s'écoule ; le diable lui apparaît de nouveau sous forme de chien tandis qu'elle se rend à Genève, et lui dit :

«Il faut que tu me rendes hommage, tu es mienne. » Elle lui rendit alors hommage. Elle embrassa son postérieur fétide qu'elle sentit être froid ${ }^{83}$. [...] Puis il la marqua au petit doigt de la main gauche comme le montre la trace où il l'a mordue ${ }^{84}$. [...] Ensuite il lui donna un petit bâton de deux pieds de long et une boîte remplie d'un onguent de couleur noire et de mauvaise odeur, lui recommandant, toutes les fois où il lui arriverait d'aller

81. S. Simon, « Si je le veux, il mourra! ». Maléfices et sorcellerie dans la campagne genevoise (1497-1530), Lausanne, 2007.

82. Ibid., p. 31-63.

83. M. OSTORERO, «L'odeur fétide des démons : une preuve de leur présence corporelle au sabbat », dans A. PARAVICINI BAGLIANI éd., Parfums et odeurs au Moyen Âge. Science, usage, symboles, Florence, 2015, p. 259-288.

84. M. OSTORERO, «Les marques du diable sur le corps des sorcières (XIV ${ }^{\mathrm{e}}$-XVII ${ }^{\mathrm{e}}$ siècles) », dans La pelle humana. Micrologus, 13 (2005), p. 359-388. 
à la synagogue, d'enduire ledit bâton dudit onguent, de le placer ensuite entre ses jambes, et de dire : «Va, de par le diable, va ! », et il lui désigna le lieu de la synagogue [...]. Aussi, le jeudi suivant, au cours de la nuit, elle prit le bâton et la boîte et fit ainsi que son maître lui avait recommandé ${ }^{85}$. Elle alla en une course rapide à ladite synagogue et trouva une assemblée de beaucoup d'hérétiques, hommes et femmes, entre lesquels se trouvait le diable, sous l'aspect d'un homme. Ils lui rendaient hommage, faisaient des révérences et l'embrassaient sur le cul. Interrogée sur ce qu'ils faisaient à ladite synagogue, elle dit qu'ils dansaient et mangeaient de la viande d'enfants [...]. Interrogée sur ce qu'ils faisaient des os des enfants apportés à la synagogue, elle dit et confessa qu'on les déposait dans le feu [de couleur verte] et qu'ils en faisaient des poudres pour faire mourir personnes et animaux, ainsi que pour faire des maléfices. [...] Et elle se confesse que quand ils se retiraient de la synagogue, le diable criait : « Meclet ! » et alors l'un connaissait l'autre et elle-même connut toujours le démon son maître. Et la matière qu'elle recevait était très froide [...]. En conséquence, elle dit et confessa que le jour où elle fut capturée, le diable, son maître, vint lui parler dans sa prison, de nuit, lui ordonnant de ne pas avouer parce qu'il la protégerait bien et conformément à cela, elle l'appela pendant la torture et les supplices, mais ne le vit pas ${ }^{86}$.

La veuve dénonce pour finir sept personnes, quatre femmes (dont deux veuves comme elle et sa propre dénonciatrice !) et trois hommes, mais on ne connaît pas l'issue (probablement funeste) de son procès. Outre les traits désormais communs au sabbat en cette toute fin de $\mathrm{XV}^{\mathrm{e}}$ siècle - l'apostasie, l'hommage au diable, le vol magique, la secte, les infanticides, les maléfices, etc.) -, on peut noter dans cette relation saisissante du crime abominable que la puissance du diable s'arrête brusquement au moment où le pouvoir du juge, ecclésiastique ici, entre en scène. Comme le note Franck Mercier, « dans l'immense champ des opérations diaboliques se découpent [...] une série d'enclaves qualifiées d'inaccessibles [...] et qui constituent bien sûr le siège de la toute-puissance divine ${ }^{87} \gg$. Dans cet ordre d'idée, la justice ecclésiastique, voire celle du prince lorsqu'elle est en première ligne, semble échapper à l'emprise démoniaque, dessinant ainsi des espaces de pleine souveraineté que l'on affirme d'autant mieux que l'on pourchasse des hérétiques qui lèse la majesté de Dieu et/ou celle de son représentant dans l'ordre temporel par des crimes sacrilèges et contrenature $^{88}$. Comme devant l'exorciste ecclésiastique investi de la puissance

85. Sur le débat autour du vol magique et sa réalité au XV e siècle, $c f$. M. OsTORERO, Le Diable au sabbat..., p. 567-700 ; F. MERCIER, La Vauderie d'Arras..., p. 233-247.

86. Ibid., p. 160-167, édition du texte latin et traduction française.

87. F. MERCIER, « 'Des choses qui surmontent la puissance des anges'... », p. 129-130.

88. Ibid., p. 130-132. 
divine ${ }^{89}$, le diable, en dépit de sa capacité à pervertir, ne peut rien en définitive face aux juges, défenseurs de l'autorité de Dieu et de l'Église, voire le cas échéant de celle du prince ; il sert en revanche, en repoussoir, à affirmer leur autorité et la souveraineté du pouvoir qu'ils représentent. Franck Mercier a particulièrement mis en évidence ces jeux de pouvoir dans le cas de la Vauderie d'Arras (1459-1460), une affaire bourguignonne qui témoigne de la diffusion de l'imaginaire du sabbat et de la persécution en périphérie de son foyer initial ${ }^{90}$. Si la procédure contre les gens d'Arras, de tous niveaux sociaux, est menée par l'inquisiteur dominicain Pierre le Broussard en collaboration avec la justice épiscopale, se profile en arrièreplan la tutelle princière, et derrière la défense de la majesté de Dieu, celle de la majesté et de la souveraineté du duc de Bourgogne Philippe le Bon : « Ni tout à fait procès d'Église, ni tout à fait procès d'État, [la vauderie] se présente plutôt comme un persécution en trompe l'œil où le religieux est intimement lié au politique, où à travers l'Église se découvre l'État ${ }^{91}$. »

Notre connaissance de cette implication à géométrie variable des pouvoirs ecclésiastiques et laïques dans la chasse aux sorciers démonolâtres vient de bénéficier de la contribution exceptionnelle livrée, au point de rencontre de l'historiographie que nous avons mentionnée, par Franck Mercier et Martine Ostorero autour de « l'énigme de la Vauderie de Lyon $^{92}{ }^{2}$. Par la découverte de nouvelles versions de la Vauderye de Lyonois en brief et d'autres documents inédits de première importance, les deux historiens sont parvenus à éclairer cette version lyonnaise de l'émergence et de la répression du sabbat et, par extension, les différentes formes d'action judiciaire menées contre les « sectes » de sorciers dans l'Est et le Nord de la France, ainsi qu'aux marges de l'Empire au cœur du $\mathrm{XV}^{\mathrm{e}}$ siècle. Daté par Joseph Hansen des alentours de 1460, il s'avère en fait que l'épisode s'est déroulé vers 1437-1439, soit au moment où les premiers textes sur l'imaginaire du sabbat étaient rédigés et où les premiers procès intervenaient dans les vallées alpines. Le petit mémoire sur la Vauderie décrit une secte de sorciers se livrant à l'horrible sabbat et aux autres crimes communément imputés aux apostats démonolâtres. Il décrit le mal nouveau - le « fait », le « martinet », la « synagogue » ou le « sabbat » - en soulignant son enormitas. Son auteur, peut-être Jean Tacot, un dominicain

89. F. Chave-Mahir, L'Exorcisme des possédés...; B. P. Levack, The Devil Within. Possession and Exorcism in the Christian West, New Haven/Londres, 2013 ; F. Young, A History of Exorcism in Catholic Christianity, Palgrave, 2016.

90. F. MERCIER, La Vauderie d'Arras...

91. Ibid., p. 139-162, ici p. 161. Sur la construction de l'État bourguignon, voir en dernier lieu É. LECUPPRE-DESJARDIN, Le Royaume inachevé des ducs de Bourgogne (XIVe$X V^{e}$ siècles), Paris, 2016.

92. F. MERCIER et M. Ostorero, L'Énigme de la Vauderie de Lyon. Enquête sur l'essor de la chasse aux sorcières entre France et Empire (1430-1480), Florence, 2015. 
du couvent de Lyon, affirme l'avoir rédigé en se fondant sur des enquêtes inquisitoriales, des procédures judiciaires, des dépositions et des aveux. Si tous les éléments de l'imaginaire du sabbat s'y trouvent (apostasie, sacrilège contre les sacrements, démonolâtrie, maléfices, etc.), il donne en particulier une description du diable que Raoul Glaber n'aurait pas reniée, qui rend compte, en quelque sorte, d'une incarnation manquée :

De même, le diable lui-même, trompant par ruse ces malheureux, se présente à eux de manière visible, toujours sous une forme effroyable, comme ils l'avouent eux-mêmes, parfois sous l'aspect d'un homme très hideux, c'est-à-dire noir, entièrement couvert de poils et hirsute, pourvu de cornes, à la figure monstrueuse, allongée et tordue, dont les yeux saillants, plus gros que ceux de tout animal qui nous est connu, brillent de flammes et roulent sans cesse dans leur orbite ; il a un grand nez crochu et ses oreilles démesurées, placées haut sur le crâne, projettent du feu ; sa bouche ouverte, aux lèvres retournées vers l'extérieur, s'allonge jusqu'aux oreilles et laisse la langue pendre à l'extérieur ; son menton monstrueusement allongé se recourbe terriblement d'un côté de la gorge ; son cou démesuré est tellement long qu'il dépasse horriblement du corps, ou alors il est trop court, de sorte que la tête semble adhérente aux épaules; il a la poitrine, le ventre et tout le reste inconcevablement vicié. Enfin ses bras et ses mains, tout comme ses jambes et ses pieds, sont hérissés de pointes ou de dards sur toute leur longueur ; les extrémités de ses mains et de ses pieds se terminent par des griffes effrayantes, comme celles des griffons [des ours ou des lions]. Mais parfois, comme ces hommes pervertis l'ont même avoué, le diable apparaît habituellement sous des formes et apparences animales, mais toujours immondes, très viles et dégoûtantes, comme celle du bouc, du renard, du gros chien, du bélier, du loup, du chat, du blaireau, du taureau, [de l'ours ou du singe] et autre. De même, ce mauvais esprit leur parle d'une voix si rauque, affreuse et dissonante, qu'ils sont saisis d'une terreur incroyable à chaque fois qu'il s'adresse à eux et qu'ils restent ensuite très longtemps à trembler d'effroi et d'horreur ${ }^{93}$.

L'histoire de la vauderie de Lyon est surtout, sur le plan judiciaire, celle d'une persécution manquée, faute de coopération entre l'inquisition dominicaine et l'officialité lyonnaise, semble-t-il réticente à souscrire à la nouveauté du crime et qui, de son côté, défendait ses prérogatives judiciaires, avec l'aide du duc de Bourbon, en s'en prenant aux juifs et aux blasphémateurs (après 1437). Les dominicains de Lyon, soutenus par le pape Eugène IV qui leur adresse la bulle contre les invocateurs de démons Ineffabilis summi providentia (décembre 1437), et placés au cœur d'un

93. Ibid., p. 62-64, texte latin et traduction française. 
vaste réseau diffusant les idées sur la «nouvelle » sorcellerie, auraient tenté, en «fabriquant» le crime de sorcellerie démoniaque, de « conquérir [une] position centrale » dans le jeu politique et religieux régional : « Nouvel objet criminel, nouveau terrain d'enquête, la sorcellerie démoniaque et sectaire devient, entre les mains de l'inquisition lyonnaise, un puissant levier pour déstabiliser l'ordre juridictionnel établi et surtout affirmer son autorité ${ }^{94}$. » Mais, en dépit de l'intervention d'une commission de jurisconsultes lyonnais, puis en dernier recours de l'appel au roi dont l'autorité souveraine se renforce alors dans la région, l'échec est patent et l'inquisition lyonnaise se trouve pour longtemps marginalisée. La conjonction entre les intérêts de l'État monarchique et ceux de l'inquisition ne s'est pas réalisée.

Cet échec se mesure aussi à l'aune des réussites voisines. À un office d'inquisition entravé sur la rive droite du Rhône répond à l'inverse une inquisition efficace dans le duché de Savoie. Y sévissent notamment les franciscains Ponce Feugeyron et Bérard Trémey, ou encore le dominicain Ulric de Torrenté qui, chacun en leur temps et dans leur juridiction, obtiennent le plein soutien d'Amédée VIII/Félix V, dont, de manière générale, la souveraineté émergente s'appuie sur une volonté de purification rigoureuse de ses terres, ce dont témoigne la législation ducale : « le combat contre l'hétérodoxie est un moyen pour le duc de Savoie d'affirmer un pouvoir souverain, en prétendant lutter pour l'intégrité de la majesté divine et humaine ${ }^{95} \gg$. Le contraste avec Lyon et le royaume de France est à cet égard éloquent. C'est également vrai avec le Dauphiné, notamment entre 1424 et 1445, où l'on assiste à une répression féroce menée par le jugemage Claude Tholosan, auteur vers 1436 du Ut magorum et maleficiorum errores $^{96}$. C'est ici la justice delphinale, et donc séculière, qui se trouve en position de force, assimilant la nouvelle hérésie au crime de lèse-majesté. Ne faut-il pas y voir une volonté d'accélérer l'intégration de cette ancienne terre d'Empire située en marge du royaume «très chrétien »? ; une nécessité qui, par comparaison, n'avait pas lieu d'être à Lyon et du «bon » côté du Rhône, comme du reste ailleurs dans le royaume, où la répression du délit de vauderie semble mise sous l'éteignoir. Dans tous les cas, au-delà des circonstances locales, la volonté dont fait montre (ou non) le pouvoir politique apparaît comme un facteur déterminant de l'efficacité de l'activité judiciaire, notamment de celle des inquisiteurs.

Les démons, qu'ils soient extérieurs ou intérieurs, qu'ils obsèdent ou qu'ils possèdent, sont, par leur activité corruptrice, les faire-valoir

94. Ibid.,p. 257.

95. Ibid., p. 297-299.

96. M. OSTORERO et al. éd., L'Imaginaire du sabbat..., p. 361-438. 
nécessaires au rehaussement de la vie humaine et à sa pleine inscription dans l'économie du salut; ils participent aussi, par la multitude d'épreuves qu'ils diligentent, à révéler la vérité du for intérieur de tout homme, sur le modèle de Job. En cette fin de Moyen Âge, par les crimes quasi indicibles qu'ils font perpétrer à leurs suppôts humains, par le risque de subversion générale qu'ils induisent, ils appellent la réplique nécessaire, implacable et victorieuse de l'Église et des pouvoir séculiers, dont l'autorité, fondée en Dieu, a une valeur exorcistique. Si l'on en croit un Rituel d'exorcisme des alentours de 1400, l'empereur Charles IV de Luxembourg aurait été l'auteur en 1365 d'exorcismes de dépossession démontrant son pouvoir démonifuge et thaumaturgique, à la manière du Christ, de son préfigurateur Salomon le sage (l'un des modèles de Charles), et de l'exorciste de l'Église que les formulaires qualifient volontiers d'imperator spiritualis ${ }^{97}$. Face aux « invocateurs de démons » que sont les magiciens et les sorciers, pouvoirs ecclésiastiques et pouvoirs séculiers, dans des configurations variables, affirment à leur tour, par la force des confessions judiciaires extorquées, leur capacité à lier les démons et à les faire obéir (et avec eux les fidèles ou les sujets), et à défendre leur souveraineté sacrée de toute intrusion, démoniaque comme humaine. La leçon est simple : pour construire un charisme ou une autorité, quelle qu'elle soit, rien n'est mieux en définitive qu'un adversaire résolu mais à coup sûr vaincu...

Julien Véronèse - Université d'Orléans/EA 4710 POLEN/CESFiMA

97. F. CHAVE-MAHIR et J. VÉRONÈSE, Rituel d'exorcisme ou manuel de magie ? Le manuscrit Clm 10085 de la Bayerische Staatsbibliothek de Munich (début du XVe siècle), Florence, 2015, p. 74-84 et 165-170 (édition du texte). 
